\title{
The incidence, risk factors, and prognosis of postoperative hyperbilirubinemia after cardiac surgery: a systematic review and meta-analysis
}

\author{
Xiaolan Chen ${ }^{1 \#}$, Ming Bai ${ }^{1 \#}$, Wei Zhang ${ }^{1}$, Shiren Sun ${ }^{1}$, Xiangmei Chen ${ }^{1,2}$ \\ ${ }^{1}$ Department of Nephrology, Xijing Hospital, The Fourth Military Medical University, Xi'an, China; ${ }^{2}$ State Key Laboratory of Kidney Disease, \\ Department of Nephrology, Chinese People's Liberation Army General Hospital and Military Medical Postgraduate College, Beijing, China \\ Contributions: (I) Conception and design: All authors; (II) Administrative support: M Bai; (III) Provision of study materials or patients: X Chen, \\ X Chen; (IV) Collection and assembly of data: X Chen, W Zhang; (V) Data analysis and interpretation: X Chen, M Bai, S Sun; (VI) Manuscript \\ writing: All authors; (VII) Final approval of manuscript: All authors. \\ \#These authors contributed equally to this work. \\ Correspondence to: Ming Bai, MD; Shiren Sun, MD. Department of Nephrology, Xijing Hospital, The Fourth Military Medical University, No. 127 \\ Changle West, Road, Xi'an 710032, China. Email: mingbai1983@126.com; sunshiren@medmail.com.cn; Xiangmei Chen, MD. State Key Laboratory \\ of Kidney Disease, Department of Nephrology, Chinese People's Liberation Army General Hospital and Military Medical Postgraduate College, \\ 28th Fuxing Road, Beijing 100853, China. Email: xmchen301@126.com.
}

Background The purpose of the present systematic review was to evaluate the incidence, risk factors, and outcome of hyperbilirubinemia after cardiac surgery.

Methods: The Population, Interventions, Comparators, Outcomes, and Study design (PICOS) framework was employed to develop the search strategy, and the findings are reported in accordance with the Preferred Reporting Items for Systematic Reviews and Meta-Analyses (PRISMA) statement. PubMed, Embase, and the Cochrane Library were systematically searched for studies that provided data on the incidence, risk factors, and outcomes of hyperbilirubinemia in cardiac surgery patients from January 1960 to May 2020. Publication bias was graphically explored through funnel plots, and the Newcastle-Ottawa quality assessment scale (NOS) was used to evaluate the quality of the included studies.

Results: Ten studies with 6,100 patients were included in our systematic review. The pooled incidence of hyperbilirubinemia was $23 \%$ [95\% confidence interval (CI), 0.13-0.32]. Preoperative factors, including right atrial pressure [mean difference (MD), 4.65; 95\% CI, 4.43-4.88], total bilirubin (TB) concentration (MD, 0.72; 95\% CI, 0.65-0.79), alkaline phosphatase (MD, 27.38; 95\% CI, 12.94-41.82), and alanine aminotransferase (MD, 12.02; 95\% CI, 10.73-13.31), and intraoperative factors, including cardiopulmonary bypass (CPB) time (MD, 1.57; 95\% CI, 0.52-2.63), aortic cross-clamping (ACC) time (MD, 11.82; 95\% CI, 9.50-14.14), and the amount of blood transfused (MD, 3.77; 95\% CI, 0.68-6.85), were the most robust risk factors for hyperbilirubinemia after cardiac surgery. Additionally, postoperative hyperbilirubinemia was associated with increased in-hospital mortality [odds ratio (OR), 9.9; 95\% CI, 5.00-19.60, P<0.0001].

Discussion: Hyperbilirubinemia was common and was associated with increased in-hospital mortality. Preoperative high right atrial pressure, high TB concentration, prolonged CPB and ACC time, and a large amount of blood transfused were the commonly observed risk factors for postoperative hyperbilirubinemia in cardiac surgery patients. Addressing these risk factors may be helpful to lower the occurrence of postoperative hyperbilirubinemia.

Keywords: Hyperbilirubinemia; cardiac surgery; risk factors; cardiopulmonary bypass (CPB)

Submitted Feb 20, 2021. Accepted for publication May 10, 2021.

doi: $10.21037 /$ apm-21-410

View this article at: https://dx.doi.org/10.21037/apm-21-410 


\section{Introduction}

More than 2 million cardiac surgeries are performed worldwide each year (1). It has long been recognized that hyperbilirubinemia is common after cardiac surgery, especially under cardiopulmonary bypass (CPB), which may be caused by hemolysis $(2,3)$, may be secondary to liver hypoperfusion $(4,5)$, or may be a systemic inflammatory response to CPB $(6)$. However, the reported incidences of hyperbilirubinemia after cardiac surgery differed with the definition of hyperbilirubinemia and the study population (7-9).

Some reports indicated that hyperbilirubinemia after cardiac surgery was associated with poor prognosis, including prolonged hospital stay and ICU stay and increased in-hospital mortality $(3,7,8,10-12)$. However, other studies showed no association between the development of postoperative hyperbilirubinemia and mortality $(13,14)$. The impact of postoperative hyperbilirubinemia on in-hospital mortality remains controversial.

Prevention of postoperative hyperbilirubinemia is essential because there are few effective treatments for it. The identification of high-risk patients would make it easier to prevent hyperbilirubinemia and further improve patient outcomes. Numerous risk factors for hyperbilirubinemia after cardiac surgery have been reported $(3,8,15)$. The pooling of these data to identify the risk factors for hyperbilirubinemia would be helpful to clinicians and clinical researchers. Therefore, we performed a systematic review and meta-analysis to summarize the incidence, risk factors, and outcomes of postoperative hyperbilirubinemia in cardiac surgery patients. We hoped to raise awareness of the significance of hyperbilirubinemia in cardiac surgery patients. We present the following article in accordance with the PRISMA reporting checklist (available at https:// dx.doi.org/10.21037/apm-21-410).

\section{Methods}

\section{Search strategy}

The study selection, data extraction, and reporting of results were all based on the Preferred Reporting Items for Systematic Reviews and Meta-Analyses (PRISMA) guidelines (16). The established Population, Interventions, Comparators, Outcomes, and Study design (PICOS) framework was employed to develop an appropriate search strategy. PubMed, Embase, and the Cochrane Database were searched for studies about the incidence and risk factors for hyperbilirubinemia and the relationship between hyperbilirubinemia and in-hospital mortality among cardiac surgery patients from January 1960 to May 2020. There was no language restriction. The following search terms were used: 'cardiac surgical procedures' or 'heart surgery' and 'hyperbilirubinemia' or 'bilirubinemia'. Full search strategies are available in Appendix 1. We further reviewed the reference lists of all of the included studies as well as relevant review articles to identify additional studies.

\section{Study selection criteria}

After removal of duplicates, two reviewers (XC and $\mathrm{MB}$ ) independently screened the titles and abstracts for potential eligibility. Articles deemed potentially relevant by either reviewer were retrieved for full-text review. Any disagreement between the reviewers was resolved by discussion. The inclusion criteria were as follows: (I) the study population was patients who underwent cardiac sugary; (II) the exposure of interest was hyperbilirubinemia; and (III) the outcome of interest was in-hospital mortality or risk factors for hyperbilirubinemia. A study was excluded if it met any of the following criteria: (I) its full text was not available; (II) it did not report the in-hospital mortality or risk factors for hyperbilirubinemia; (III) it had an unclear definition of hyperbilirubinemia; and (IV) it was a review, case report, letter, editorial, conference abstract, or comment.

\section{Data extraction and quality evaluation}

Data were extracted from the eligible studies and summarized in a standardized data extraction form, which included the author's name, year of publication, study design, cohort description, definition of hyperbilirubinemia, number of patients, incidence of postoperative hyperbilirubinemia, risk factors for hyperbilirubinemia, hospital deaths in the hyperbilirubinemia group and non-hyperbilirubinemia group, and any other data the reviewers deemed relevant. In the case of missing data, the corresponding authors were emailed to ask for the missing data.

A modified Newcastle-Ottawa quality assessment scale (NOS) was employed to evaluate study quality (17). This scale awards a maximum of nine stars to each study: four stars for selection of participants and measurement of exposure, two stars for comparability, and three stars for assessment of outcomes and adequacy of follow-up. 


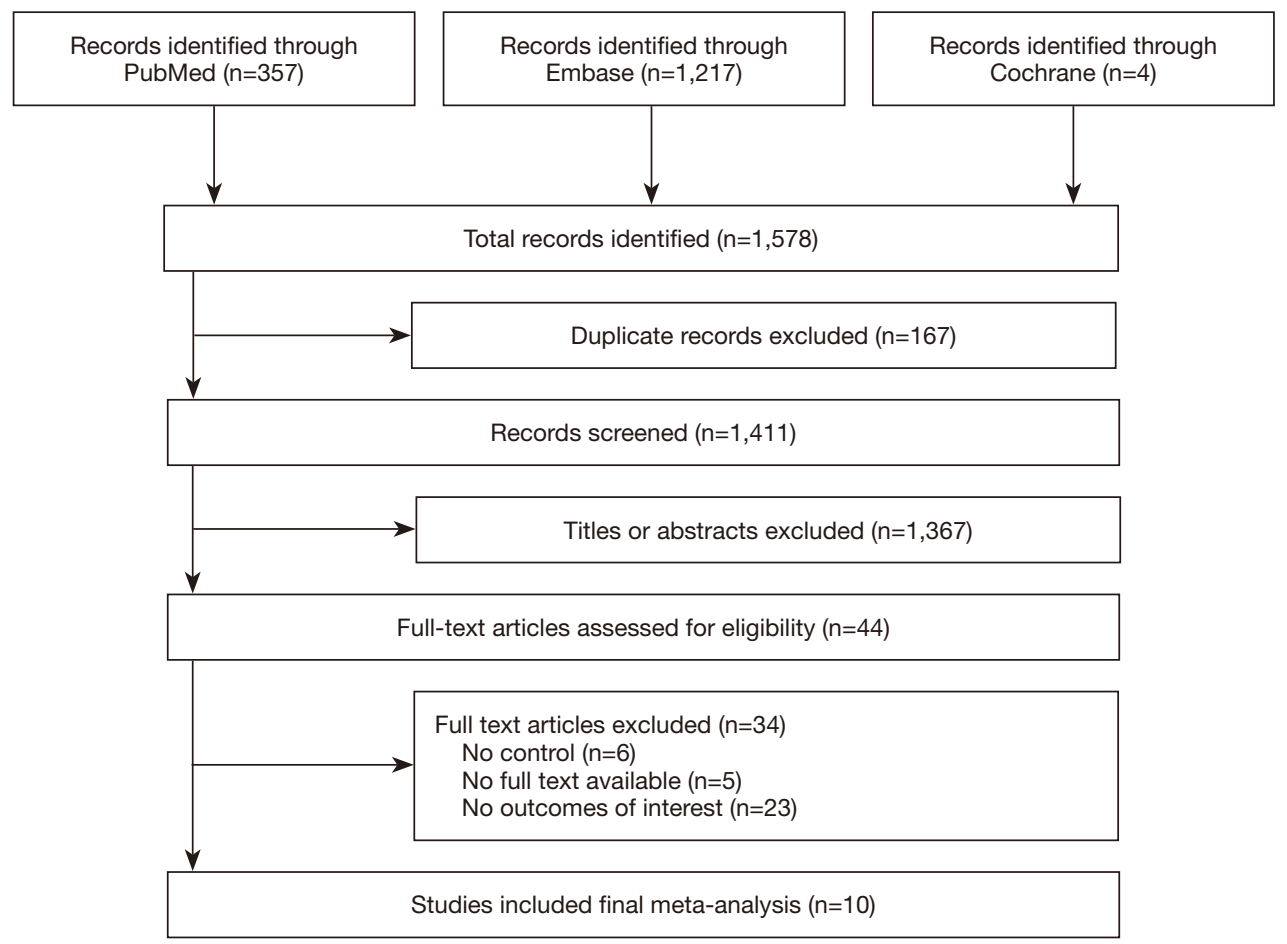

Figure 1 Flow diagram of study selection.

\section{Statistical analysis}

A fixed-effects model was used when the study heterogeneity was not statistically significant, and a random-effects model was used when the heterogeneity was statistically significant. Pooled estimates were obtained for the incidence of hyperbilirubinemia and hospital mortality, which were reported using a random-effects meta-analysis based on the methods of DerSimonian and Laird. Risk factors that were investigated by more than two studies were pooled. The odds ratio [OR; $95 \%$ confidence interval (CI)] and mean difference (MD; 95\% CI) were used to illustrate the comprehensive effects of hyperbilirubinemia occurring in cardiac surgery patients. For continuous variables, the MD and $95 \% \mathrm{CI}$ were calculated. MD was the measure of the difference in a specific risk factor between individuals with hyperbilirubinemia and those without hyperbilirubinemia. Study heterogeneity was assessed using the $\mathrm{I}^{2}$ statistic. Subgroup and sensitivity analyses were used to explore the potential sources of heterogeneity. Statistical significance was set at $\mathrm{P}<0.05$ (two-tailed). Publication bias was graphically explored through a funnel plot, and funnel plot symmetry was assessed with Egger's test. Statistical analysis was carried out by using RevMan, version 5.3 (The Cochrane Collaboration), Stata 14.0 software (Stata Corp
LP, College Station, TX, USA), and Comprehensive Meta Analysis version V2.

\section{Results}

\section{Search results and study characteristics}

The process for the literature search and study selection is summarized in Figure 1. A total of 1,578 records were retrieved by our search strategy, and 44 articles were identified as potentially relevant based on title and abstract review. These underwent full-text review. Finally, 10 studies with 6,100 subjects were included in the present systematic review $(3,7-10,12-15,18)$.

The characteristics of the included studies are summarized in Table 1. All of the included studies were observational in design. Seven $(70 \%)$ of the included studies enrolled prospective cohorts $(3,8-10,13-15,18)$. Of these included studies, the criterion for hyperbilirubinemia diagnosis was lower than $3 \mathrm{mg} / \mathrm{dL}$ in 4 studies and higher than $3 \mathrm{mg} / \mathrm{dL}$ in 6 studies. In 9 of the 10 studies, all participants underwent $\mathrm{CPB}$ cardiac surgery. One study included only valve replacement patients (8), one study included only heart transplant patients (7), and the remaining seven studies included different types of $\mathrm{CPB}$ 


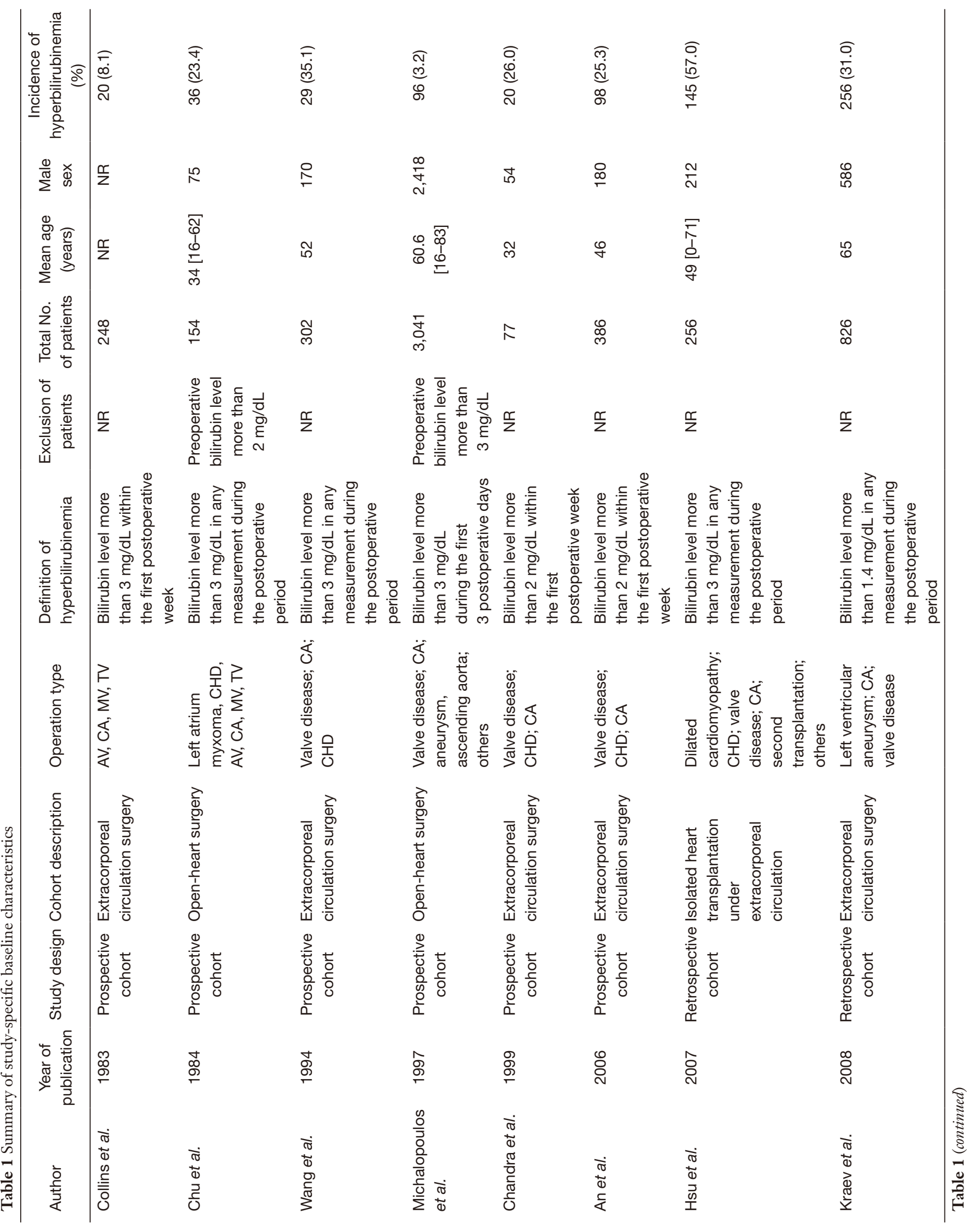




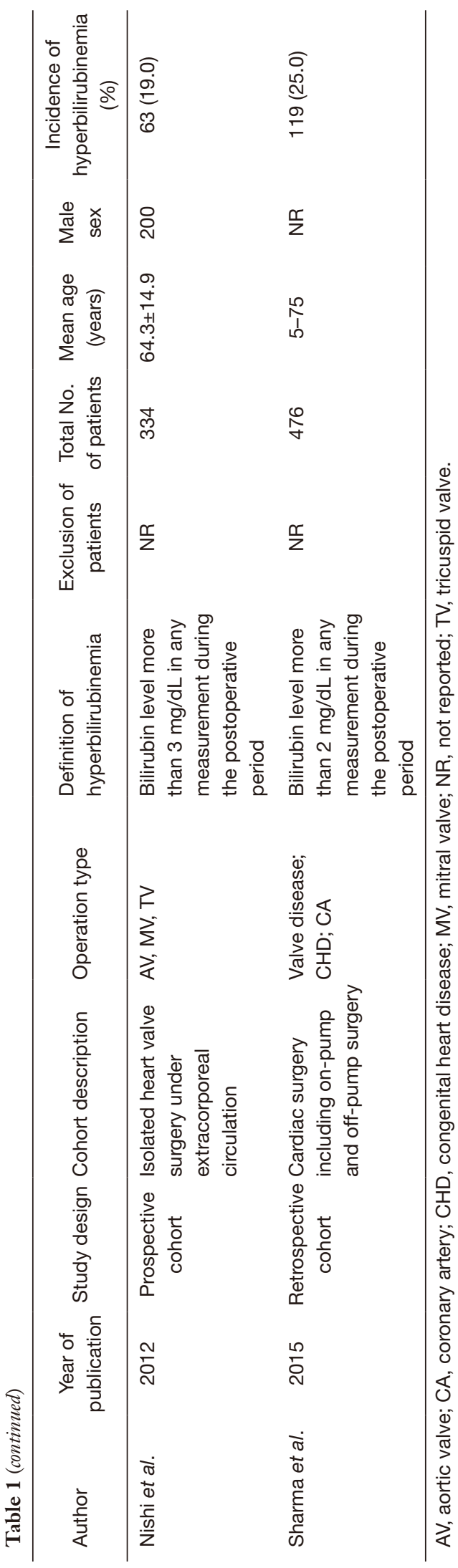

cardiac surgery patients $(3,10,12-15,18)$. The study sample size was greater than 100 in 9 studies. The scores of the individual studies on the NOS are presented in Table S1. All of the included studies scored $>6$, which indicated high quality.

\section{The incidence of hyperbilirubinemia}

The cut-off values to define hyperbilirubinemia used in the individual studies varied (Table 1). The 10 included studies enrolled a total of 6,100 participants, of whom 847 had hyperbilirubinemia after cardiac surgery. In the random-effects meta-analysis, the pooled incidence of hyperbilirubinemia for patients who underwent cardiac surgery was $23 \%$ (95\% CI, $\left.0.13-0.32, \mathrm{I}^{2}=98.9 \%\right)$. Subgroup analysis was performed by study design (Figure $2 A$ ) and definition of hyperbilirubinemia (Figure $2 B$ ). The pooled hyperbilirubinemia incidences of the seven prospective cohort studies and the three retrospective cohort studies were $17 \%$ (95\% CI, 0.08-0.26; $\mathrm{I}^{2}=98.5 \%$ ) and 36\% (95\% CI, 0.18-0.53; $\left.\mathrm{I}^{2}=97.6 \%\right)$, respectively. The pooled hyperbilirubinemia incidences of the 6 studies with a hyperbilirubinemia criterion higher than $3 \mathrm{mg} / \mathrm{dL}$ and the 4 studies with a hyperbilirubinemia criterion lower than $3 \mathrm{mg} / \mathrm{dL}$ were $20 \%$ (95\% CI, 0.09-0.31; $\mathrm{I}^{2}=98.7 \%$ ) and $27 \%$ (95\% CI, 0.24-0.31; $\left.\mathrm{I}^{2}=58.6 \%\right)$, respectively. Other sensitivity analyses, including that with the exclusion of studies with smaller samples (14), studies in nonemergency surgery patients (9), studies in heart transplantation patients (7), and studies in isolated valve surgery patients (8), did not reduce the heterogeneity to $<50 \%$ (Table S2).

\section{The risk factors for postoperative hyperbilirubinemia}

Thirteen preoperative and intraoperative variables were reported as risk factors for postoperative hyperbilirubinemia (Table 2 and Figure S1). The meta-analysis results identified eight risk factors for postoperative hyperbilirubinemia, which included preoperative right atrial pressure (MD, $4.65 \mathrm{mmHg}$; 95\% CI, 4.43-4.88), preoperative bilirubin concentration (MD, $0.72 \mu \mathrm{mol} / \mathrm{L}$; 95\% CI, 0.65-0.79), elevated preoperative bilirubin level (OR, 60.34; 95\% CI, 9.64-377.81), preoperative alkaline phosphatase (MD, 27.38 U/dL; 95\% CI, 12.94-41.82), preoperative alanine aminotransferase (MD, $12.02 \mathrm{U} / \mathrm{dL}$; 95\% CI, 10.73-13.31), the amount of blood transfused (MD, $3.77 \mathrm{U} ; 95 \% \mathrm{CI}$, 0.68-6.85), CPB time (MD, $1.57 \mathrm{~min}$; 95\% CI, 0.52-2.63), and aortic cross-clamp (ACC) time (MD, $11.82 \mathrm{~min}$; 95\% 
A Study

ID
ES $(95 \% \mathrm{Cl}) \quad$ Weight

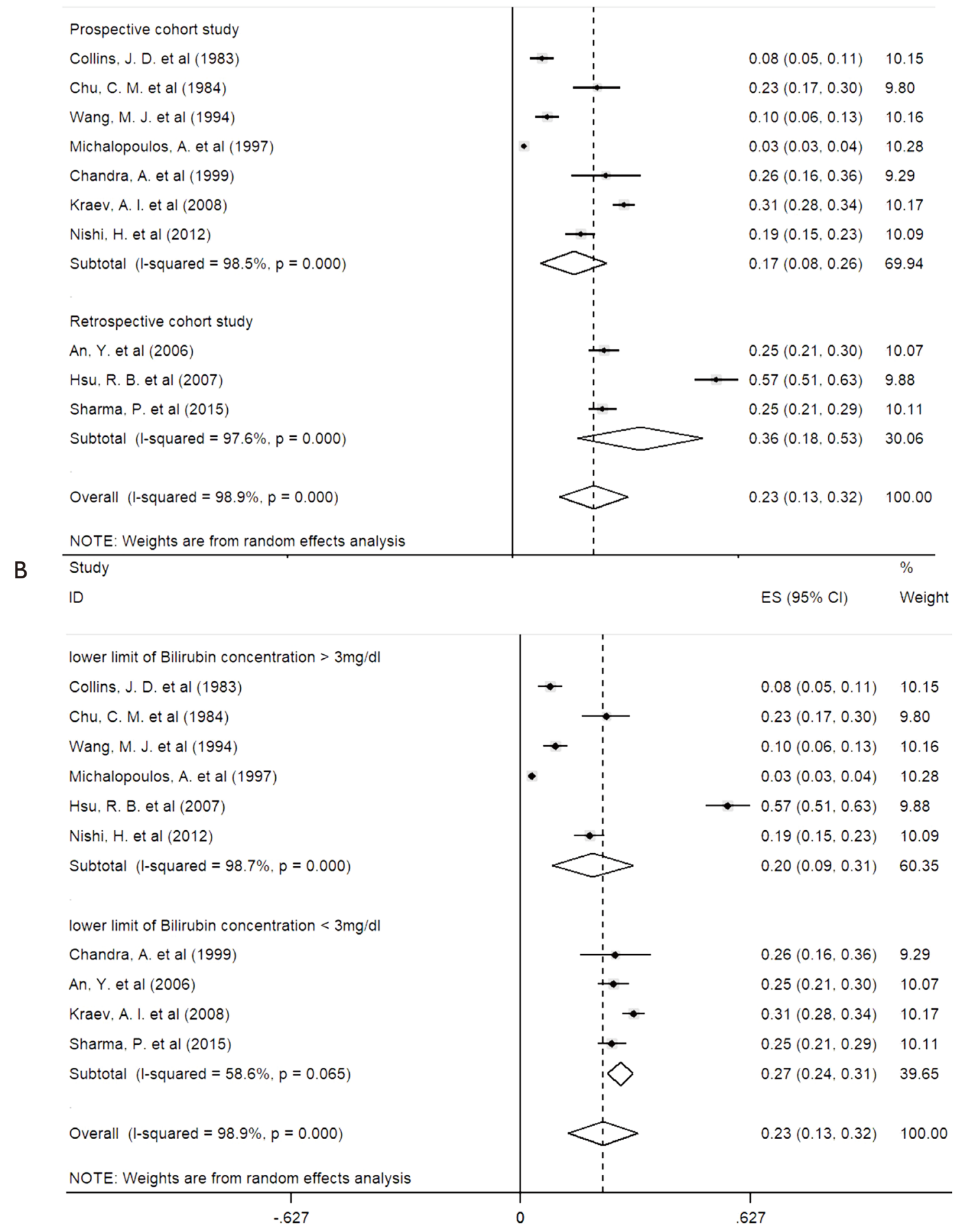

Figure 2 The pooled incidences of hyperbilirubinemia after cardiac surgery. The included studies were divided according to the definition of hyperbilirubinemia (A) and the study design (B). ES, effect size; CI, confidence interval. 
Table 2 Preoperative and intraoperative clinical variables associated with postoperative hyperbilirubinemia

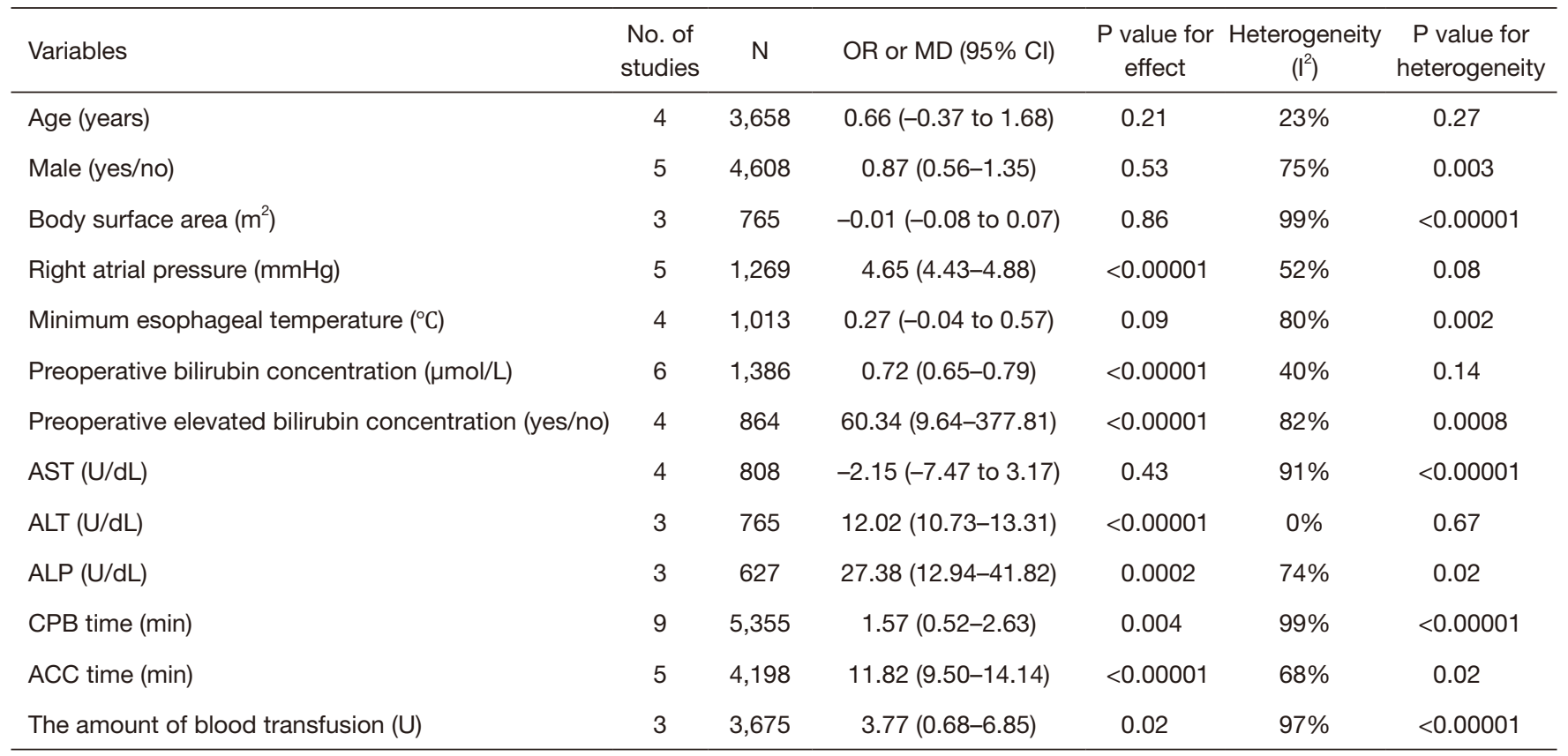

$\mathrm{OR}$, odds ratio; $\mathrm{MD}$, mean difference; $\mathrm{Cl}$, confidence interval; AST, aspartateamino transferase; ALT, alanine aminotransferase; ALP, alkaline phosphatase; CPB, cardiopulmonary bypass; ACC, aortic cross-clamp.

CI, 9.50-14.14). Age (MD, 0.66 years; $95 \% \mathrm{CI},-0.73$ to 1.68), male sex (OR, 0.87 ; $95 \%$ CI, $0.56-1.35)$, body surface area (MD, $-0.01 \mathrm{~m}^{2} ; 95 \% \mathrm{CI},-0.08$ to 0.07$)$, aspartate aminotransferase (MD, $-2.15 \mathrm{U} / \mathrm{dL} ; 95 \% \mathrm{CI},-7.47$ to $3.17)$, and minimum esophageal temperature $\left(\mathrm{MD}, 0.27^{\circ} \mathrm{C}\right.$; $95 \% \mathrm{CI},-0.04$ to 0.57 ) were not statistically associated with postoperative hyperbilirubinemia in the meta-analysis.

\section{Outcomes of byperbilirubinemia}

Nine (5,941 participants) of the 10 studies provided the in-hospital mortality data of the hyperbilirubinemia group and no-hyperbilirubinemia group. Overall, the pooled in-hospital mortality was $14.1 \%$ and $1.7 \%$ for the hyperbilirubinemia and no-hyperbilirubinemia patients, respectively. The pooled results demonstrated that hyperbilirubinemia was associated with increased patient inhospital mortality (OR, 9.9, 95\% CI, 5.00-19.60, $\mathrm{P}<0.0001$; $\left.\mathrm{I}^{2}=66 \%\right)$. Similar results were found in all subgroup analyses (Figure 3). The sensitivity analysis demonstrated that the heterogeneity was significantly reduced $\left(\mathrm{I}^{2}<50 \%\right)$ after the exclusion of the study in nonemergency surgery patients (9) or the study with a sample size $<100$ (14) (Table S3).

Additionally, the pooled results demonstrated that the occurrence of hyperbilirubinemia was associated with increased hospital stay (three studies; 3,594 patients; MD, 6.46 days; $95 \%$ CI, 0.78-12.14, $\mathrm{P}=0.04$ ) and ICU stay (five studies; 4,282 patients; MD, 5.06 days; 95\% CI, 0.15-9.97, $\mathrm{P}=0.04$ ) (Figure S2).

\section{Publication bias}

Funnel plots to evaluate the publication bias in the inhospital mortality risk of cardiac surgery patients are summarized in online Figure S3. Egger's test indicated that the publication bias was not significant in the selected studies $(\mathrm{P}=0.27)$.

\section{Discussion}

Our present meta-analysis mainly summarized the incidences, risk factors, and outcomes of hyperbilirubinemia after cardiac surgery. Our study reports the following findings: (I) the occurrence of hyperbilirubinemia was $23 \%$ after cardiac surgery; (II) four preoperative factors (high right atrial pressure, high bilirubin concentration, high alanine aminotransferase concentration, and high alkaline phosphatase concentration) and 3 intraoperative 


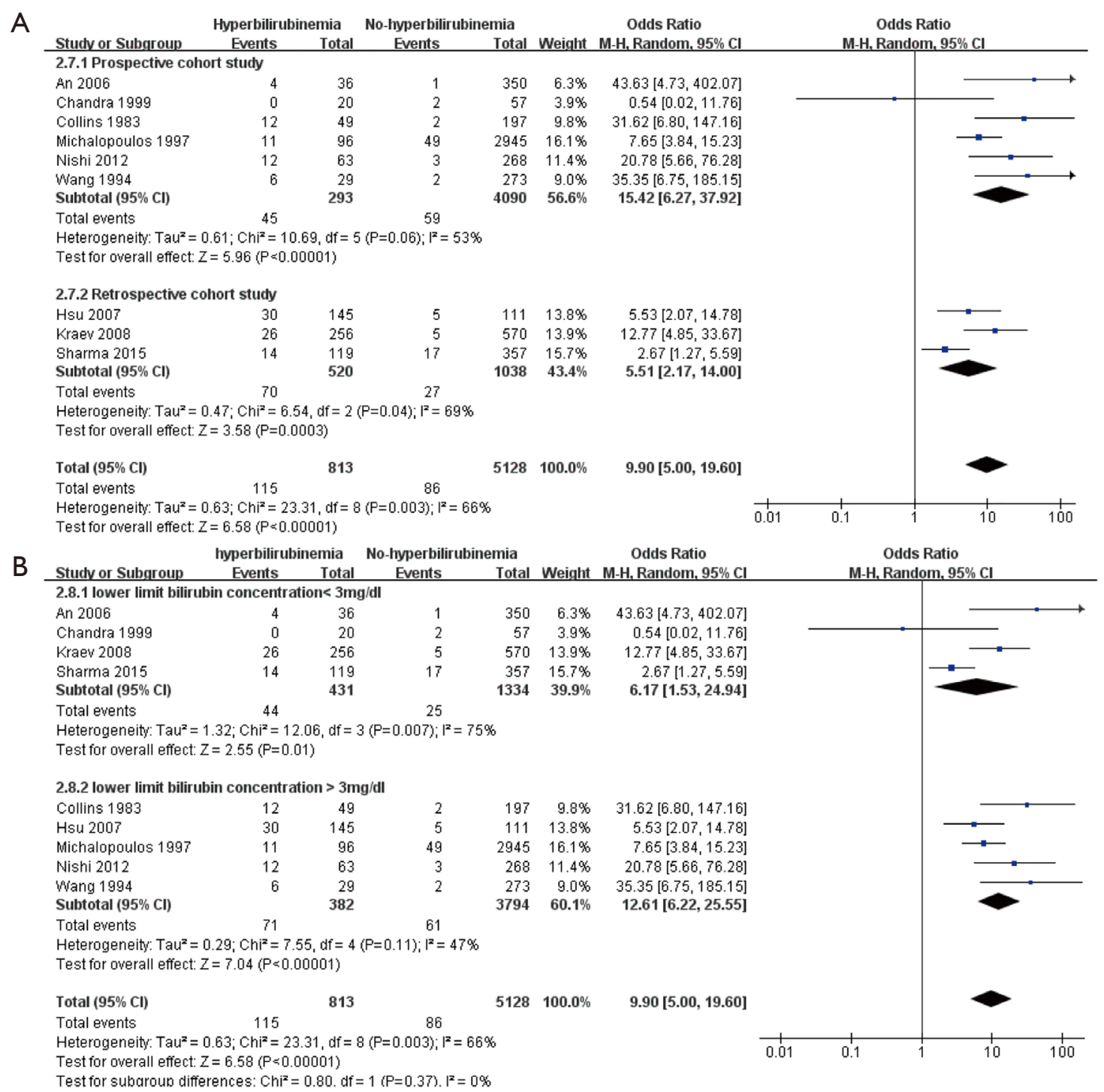

Figure 3 The pooled correlation between postoperative hyperbilirubinemia and in-hospital mortality. The included studies were divided according to the study design (A) and the definition of hyperbilirubinemia (B). CI, confidence interval.

factors (prolonged CPB time, prolonged ACC time, and increased blood transfusion) were identified as the most robust risk factors for postoperative hyperbilirubinemia; and (III) postoperative hyperbilirubinemia was associated with increased patient in-hospital mortality.

\section{The high incidence of hyperbilirubinemia}

Regardless of the type of cardiac surgery, postoperative hyperbilirubinemia was a very common complication, with a pooled incidence of $23 \%$. We found that the pooled incidence of postoperative hyperbilirubinemia in prospective cohort studies was dramatically lower than that in retrospective cohort studies (17\% vs. 36\%). One of the most likely potential reasons is that more retrospective studies employed the hyperbilirubinemia criterion $<3 \mathrm{mg} / \mathrm{dL}$. Additionally, in the sensitivity analysis, the pooled incidence of hyperbilirubinemia was significantly reduced after the exclusion of heart transplant patients from the study (7) (23\% vs. 19\%). Heart transplant recipients usually had poor heart and liver function before heart transplantation (7), which most likely was the major cause of their high risk of hyperbilirubinemia. 


\section{The risk factors for hyperbilirubinemia}

Identification of the risk factors for postoperative hyperbilirubinemia in patients who undergo cardiac surgery is essential to prevent hyperbilirubinemia and improve patient outcomes. Our meta-analysis indicated that some preoperative factors, including right atrial pressure and preoperative bilirubin concentration, significantly increased the risk of postoperative hyperbilirubinemia. Higher right atrial pressure might be associated with a "congested" state of the liver due to severe preoperative cardiac failure, which might lead to inappropriate oxygen delivery and an energy deficit and thus impair its capacity to dispose of its bilirubin load $(3,13)$, as reflected in the higher preoperative total bilirubin (TB) levels. Kraev et al. (12) further found that preoperative congestive heart failure was an independent risk factor for postoperative hyperbilirubinemia. Therefore, preoperative optimization of cardiac function, such as the control of heart failure, might be useful to reduce the occurrence of postoperative hyperbilirubinemia.

Some intraoperative factors, such as CPB time and ACC time, were associated with postoperative hyperbilirubinemia in our systematic review. Longer CPB and ACC times can lead to more hemolysis, and a longer time on the circuit can lead to changes in the perfusion of the viscera and to more inflammatory action. CPB itself might also induce hypoperfusion of abdominal organs, hypoxia (19) or an inflammatory reaction (20), consequently causing liver injury and increasing the risk of hyperbilirubinemia (8). Hemolysis of the transfused blood was another common cause of postoperative hyperbilirubinemia. The pooled results confirmed that the amount of blood transfused before and during cardiac surgery was a robust risk factor for postoperative hyperbilirubinemia. Therefore, optimizing preoperative liver protection in cases with a longer anticipated CPB time, such as when there are conditions requiring complex surgical procedures, and optimizing the surgery to reduce $\mathrm{CPB}$ time may be ways to reduce the occurrence of hyperbilirubinemia.

\section{The outcomes of hyperbilirubinemia}

The results on the impact of hyperbilirubinemia after cardiac surgery on mortality reported in different studies were conflicting. Our pooled results indicated that postoperative hyperbilirubinemia was associated with a nearly 9-fold increase in in-hospital mortality.
Subgroup analysis based on study design and definition of hyperbilirubinemia indicated that hyperbilirubinemia significantly increased in-hospital mortality as well, which indicated that this result was robust. In the sensitivity analysis, we found that the pooled risk of mortality for hyperbilirubinemia was significantly increased after the exclusion of the study in nonemergency surgery patients (9). Emergency procedures have been identified as an independent risk factor for mortality in hyperbilirubinemia patients who undergo cardiac surgery (21). Emergency surgery reflects the critical state of cardiac surgery patients, and the situation usually involves cardiac tamponade or massive blood loss, reducing cardiac output and effective blood volume. Furthermore, systemic inflammatory response syndrome, sepsis, and septic shock are common in patients undergoing emergency surgery (22), which is most likely the major cause of a high risk of mortality. The mechanism underlying the postoperative hyperbilirubinemia associated with mortality after cardiac surgery may be related to secondary liver failure, cardiac failure, and multiple-organ dysfunction syndrome. Farag et al. (21) found that multiple-organ failure, respiratory failure, septic shock, and hemorrhagic shock were strongly correlated with in-hospital mortality in patients with hyperbilirubinemia after cardiac surgery. Recent research in our center found that multiple-organ failure, heart failure, sepsis, and hemorrhagic shock were associated with in-hospital mortality among severe hyperbilirubinemia patients undergoing surgical repair of type A aortic dissection as well (23).

\section{Study limitations}

The present study had several limitations. First, the majority of data collected were based on univariate analysis. Therefore, there might have been confounding factors that were not accounted for in our study. Second, the included studies were in similar but not identical clinical setting, and the sample sizes were not large. Large-scale clinical trials are needed to verify the strength of the relationship between these risk factors and the occurrence of hyperbilirubinemia. Further studies should also determine the weight of these risk factors to make them more feasible to apply in clinical routines. Third, all of the included studies were observational studies. However, half of the included studies were prospectively designed, which guaranteed the quality of our present systematic review. Finally, we were 
unable to estimate long-term survival of patients in the hyperbilirubinemia and control groups due to incomplete data. Large cohort studies are urgently needed to estimate the long-term survival of hyperbilirubinemia patients.

\section{Conclusions}

Hyperbilirubinemia was very common after cardiac surgery. Postoperative hyperbilirubinemia was significantly associated with increased in-hospital mortality. Patients with higher preoperative right atrial pressure, elevated preoperative bilirubin, increased amount of blood transfused, and prolonged $\mathrm{CPB}$ and ACC time had a higher risk of postoperative hyperbilirubinemia. Addressing these risk factors may be helpful to lower the occurrence of postoperative hyperbilirubinemia.

\section{Acknowledgments}

Funding: This work was supported by the National Natural Science Foundation of China (82070699) and Discipline Promotion Project of Xijing Hospital (XJZT18ML16).

\section{Footnote}

Reporting Checklist: The authors have completed the PRISMA reporting checklist. Available at https://dx.doi. org/10.21037/apm-21-410

Conflicts of Interest: All authors have completed the ICMJE uniform disclosure form (available at https://dx.doi. org/10.21037/apm-21-410). The authors have no conflicts of interest to declare.

Ethical Statement: The authors are accountable for all aspects of the work in ensuring that questions related to the accuracy or integrity of any part of the work are appropriately investigated and resolved.

Open Access Statement: This is an Open Access article distributed in accordance with the Creative Commons Attribution-NonCommercial-NoDerivs 4.0 International License (CC BY-NC-ND 4.0), which permits the noncommercial replication and distribution of the article with the strict proviso that no changes or edits are made and the original work is properly cited (including links to both the formal publication through the relevant DOI and the license). See: https://creativecommons.org/licenses/by-nc-nd/4.0/.

\section{References}

1. Weisse AB. Cardiac surgery: a century of progress. Tex Heart Inst J 2011;38:486-90.

2. Collins JD, Bassendine MF, Ferner R, et al. Incidence and prognostic importance of jaundice after cardiopulmonary bypass surgery. Lancet 1983;1:1119-23.

3. Wang MJ, Chao A, Huang CH, et al. Hyperbilirubinemia after cardiac operation. Incidence, risk factors, and clinical significance. J Thorac Cardiovasc Surg 1994;108:429-36.

4. Gårdebäck M, Settergren G, Brodin LA. Hepatic blood flow and right ventricular function during cardiac surgery assessed by transesophageal echocardiography. J Cardiothorac Vasc Anesth 1996;10:318-22.

5. Kumle B, Boldt J, Suttner SW, et al. Influence of prolonged cardiopulmonary bypass times on splanchnic perfusion and markers of splanchnic organ function. Ann Thorac Surg 2003;75:1558-64. Retraction in: Ann Thorac Surg 2011;92:412.

6. Levy JH, Tanaka KA. Inflammatory response to cardiopulmonary bypass. Ann Thorac Surg 2003; 75:S715-20.

7. Hsu RB, Lin FY, Chen RJ, et al. Incidence, risk factors, and prognosis of postoperative hyperbilirubinemia after heart transplantation. Eur J Cardiothorac Surg 2007;32:917-22.

8. Nishi H, Sakaguchi T, Miyagawa S, et al. Frequency, risk factors and prognosis of postoperative hyperbilirubinemia after heart valve surgery. Cardiology 2012;122:12-9.

9. Sharma P, Ananthanarayanan C, Vaidhya N, et al. Hyperbilirubinemia after cardiac surgery: An observational study. Asian Cardiovasc Thorac Ann 2015;23:1039-43.

10. Collins JD, Ferner R, Bassendine MF. Incidence and prognostic importance of jaundice after cardiopulmonary bypass surgery. Lancet 1983;1:1119-23.

11. Hosotsubo KK, Nishimura M, Nishimura S. Hyperbilirubinaemia after major thoracic surgery: Comparison between open-heart surgery and oesophagectomy. Critical Care 2000;4:180-7.

12. Kraev AI, Torosoff MT, Fabian T, et al. Postoperative hyperbilirubinemia is an independent predictor of longterm outcomes after cardiopulmonary bypass. J Am Coll Surg 2008;206:645-53.

13. Chu CM, Chang CH, Liaw YF, et al. Jaundice after open heart surgery: a prospective study. Thorax 1984;39:52-6.

14. Chandra A, Gupta D, Saibaba KSS, et al.

Hyperbilirubinemia after cardiopulmonary bypass: a prospective study. Asian Cardiovasc Thorac Ann 
1999;7:3-8.

15. An Y, Xiao YB, Zhong QJ. Hyperbilirubinemia after extracorporeal circulation surgery: a recent and prospective study. World J Gastroenterol 2006;12:6722-6.

16. Moher D, Liberati A, Tetzlaff J, et al. Preferred reporting items for systematic reviews and meta-analyses: the PRISMA statement. J Clin Epidemiol 2009;62:1006-12.

17. Lo CK, Mertz D, Loeb M. Newcastle-Ottawa Scale: comparing reviewers' to authors' assessments. BMC Med Res Methodol 2014;14:45.

18. Michalopoulos A, Alivizatos P, Geroulanos S. Hepatic dysfunction following cardiac surgery: determinants and consequences. Hepatogastroenterology 1997;44:779-83.

19. D'Ancona G, Baillot R, Poirier B, et al. Determinants of gastrointestinal complications in cardiac surgery. Tex Heart Inst J 2003;30:280-5.

Cite this article as: Chen X, Bai M, Zhang W, Sun S, Chen X. The incidence, risk factors, and prognosis of postoperative hyperbilirubinemia after cardiac surgery: a systematic review and meta-analysis. Ann Palliat Med 2021;10(7):7247-7257. doi: 10.21037/apm-21-410
20. Paparella D, Yau TM, Young E. Cardiopulmonary bypass induced inflammation: pathophysiology and treatment. An update. Eur J Cardiothorac Surg 2002;21:232-44.

21. Farag M, Veres G, Szabo G, et al. Hyperbilirubinaemia after cardiac surgery: the point of no return. ESC Heart Fail 2019;6:694-700.

22. Mullen MG, Michaels AD, Mehaffey JH, et al. Risk associated with complications and mortality after urgent surgery vs elective and emergency surgery: implications for defining "quality" and reporting outcomes for urgent surgery. JAMA Surg 2017;152:768-74.

23. Chen X, Bai M, Zhao L, et al. Characteristics and outcomes of Stanford type A aortic dissection patients with severe post-operation hyperbilirubinemia: a retrospective cohort study. J Cardiothorac Surg 2020;15:195. 


\section{Search strategies}

\section{PubMed search strategy}

\#1: Cardiac Surgical Procedures [mh]

\#2: Cardiac Surgical Procedures or Procedure, Cardiac Surgical or Procedures, Cardiac Surgical or Surgical Procedure, Cardiac or Surgical Procedures, Cardiac or Surgical Procedures, Heart or Cardiac Surgical Procedure or Heart Surgical Procedures or Procedure, Heart Surgical or Procedures, Heart Surgical or Surgical Procedure, Heart or Heart Surgical Procedure or cardiopulmonary bypass or extracorporeal circulation \#3: \#1 or \#2

\#4: Hyperbilirubinemia [mh]

\#5: Hyperbilirubinemia or Hyperbilirubinemias or Bilirubinemia or Bilirubinemias

\#6: \#4 or \#5

\#: \#3 and \#6

1,217 Search results.

Results obtained May 29, 2020.

\section{Cochrance search strategy}

\#1: Cardiac Surgical Procedures or Procedure, Cardiac Surgical or Procedures, Cardiac Surgical or Surgical Procedure, Cardiac or Surgical Procedures, Cardiac or Surgical Procedures, Heart or Cardiac Surgical Procedure or Heart Surgical Procedures or Procedure, Heart Surgical or Procedures, Heart Surgical or Surgical Procedure, Heart or Heart Surgical Procedure or cardiopulmonary bypass or extracorporeal circulation \#2: Hyperbilirubinemias or Bilirubinemia or Bilirubinemias

\#3: \#1 and \#2

4 Search results.

Results obtained May 29, 2020.

\section{Embase search strategy}

\#1: "heart surgery"/exp

\#2: "heart surgery" or "cardiac surgery" or "cardiac surgical procedures" or "cardiosurgery" or "heart operation" or "myocardial resection" or "surgery, heart" or "extracorporeal circulation" or "cardiopulmonary bypass"

\#3: \#1 or \#2

\#4: "hyperbilirubinemia"/exp

\#5: "bilirubinaemia" or "bilirubinemia" or "hyperbilirubinaemia" or "hyperbilirubinaemia" or "hereditary" or "hyperbilirubinemia, hereditary" \#6: \#4 or \#5

$\# 7: \# 3$ and \#6

357 Search results.

Results obtained May 29, 2020. 
Table S1 NOS of included studies

\begin{tabular}{|c|c|c|c|c|c|c|c|c|c|}
\hline \multirow[b]{2}{*}{ Author } & \multicolumn{4}{|c|}{ Selection } & \multirow[b]{2}{*}{ Comparability } & \multicolumn{3}{|c|}{ Outcomes } & \multirow[b]{2}{*}{ Total score } \\
\hline & $\begin{array}{l}\text { Exposed } \\
\text { cohort }\end{array}$ & $\begin{array}{l}\text { Nonexposed } \\
\text { cohort }\end{array}$ & $\begin{array}{l}\text { Ascertainment of } \\
\text { exposure }\end{array}$ & $\begin{array}{l}\text { Outcome of } \\
\text { interest }\end{array}$ & & $\begin{array}{l}\text { Assessment of } \\
\text { outcome }\end{array}$ & $\begin{array}{l}\text { Length of } \\
\text { follow-up }\end{array}$ & $\begin{array}{l}\text { Adequacy of } \\
\text { follow-up }\end{array}$ & \\
\hline Collins et al. & * & * & * & * & * & * & $\ldots$ & $\ldots$ & 6 \\
\hline Chu et al. & * & * & * & * & * & $\ldots$ & $\ldots$ & $\ldots$ & 6 \\
\hline Wang et al. & * & * & * & * & * & * & .... & $\ldots$ & 6 \\
\hline Michalopoulos et al. & * & * & * & * & * & * & $\ldots$. & $\ldots$ & 7 \\
\hline Chandra et al. & * & * & * & * & * & * & $\ldots$ & $\ldots$ & 6 \\
\hline An et al. & * & * & * & * & * & * & .... & $\ldots$ & 6 \\
\hline Hsu et al. & * & * & * & * & * & * & * & * & 8 \\
\hline Kraev et al. & * & * & * & * & * & * & * & * & 8 \\
\hline Nishi et al. & * & * & * & * & * & * & $\ldots$ & $\ldots$ & 6 \\
\hline Sharma et al. & * & * & * & * & * & * & $\ldots$. & $\ldots$. & 6 \\
\hline
\end{tabular}

*, assessment quality; ..., not mentioned. NOS, Newcastle-Ottawa quality assessment scale.

Table S2 Sensitivity analyses of pooled incidence of hyperbilirubinemia

\begin{tabular}{lccc}
\hline Excluding studies & No. of studies & Incidence rate $(95 \% \mathrm{Cl})$ & Heterogeneity $\left(\mathbb{I}^{2}\right)$ \\
\hline$<100$ participants & 9 & $0.22(0.12-0.32)$ & $98.90 \%$ \\
Including off-pump surgery & 9 & $0.22(0.12-0.32)$ & $98.90 \%$ \\
Isolated heart valve surgery & 8 & $0.23(0.13-0.33)$ & $99.00 \%$ \\
Isolated heart transplantation & 8 & $0.19(0.09-0.28)$ & $98.60 \%$ \\
\hline
\end{tabular}

Isolated heart transplantation

$0.19(0.09-0.28)$

$98.60 \%$

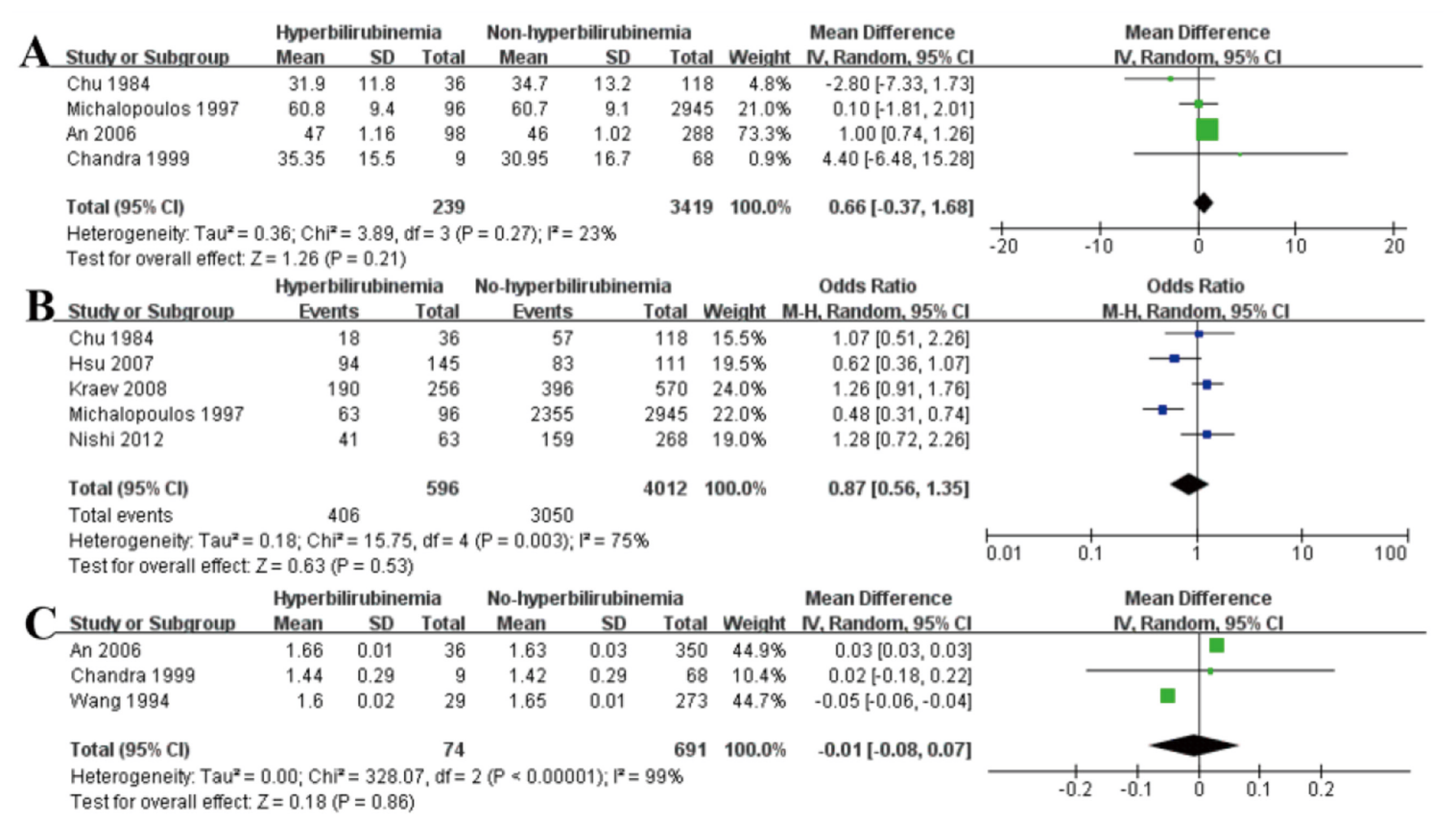

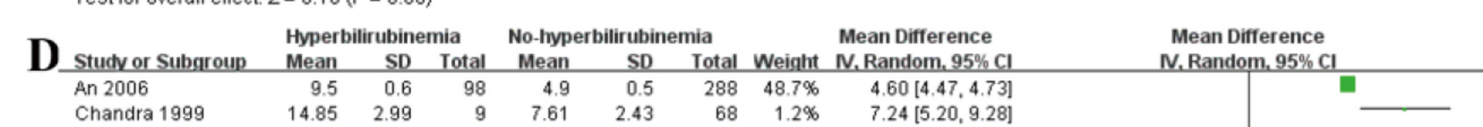

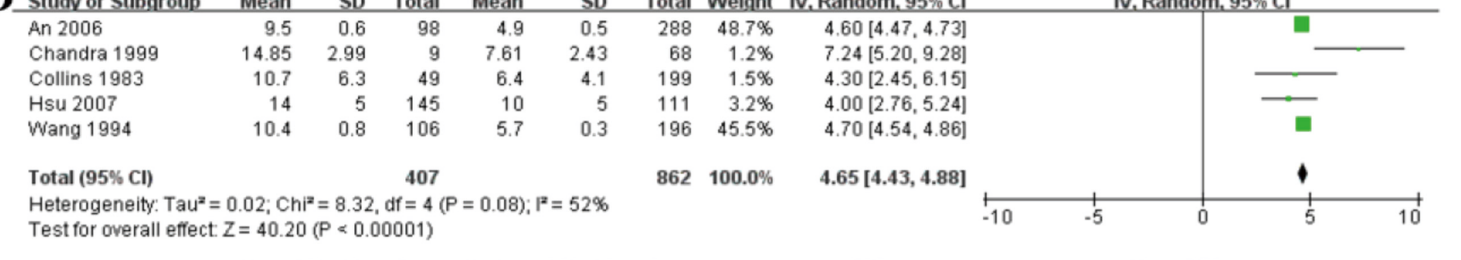

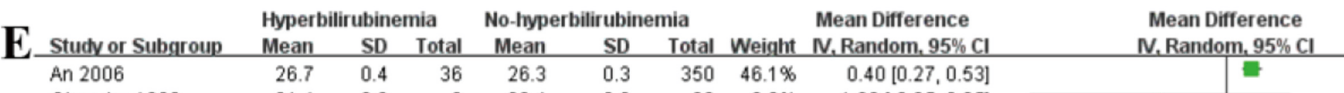

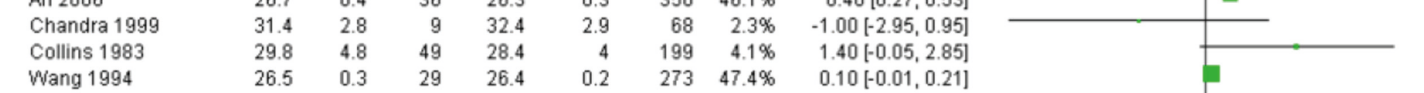

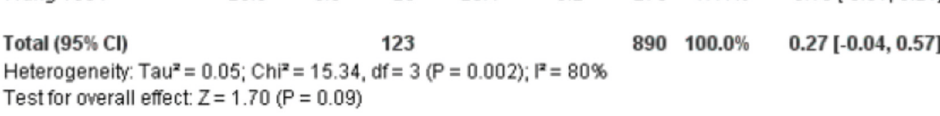

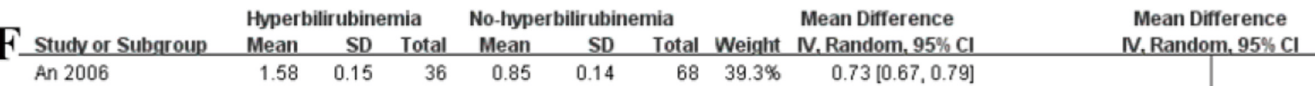

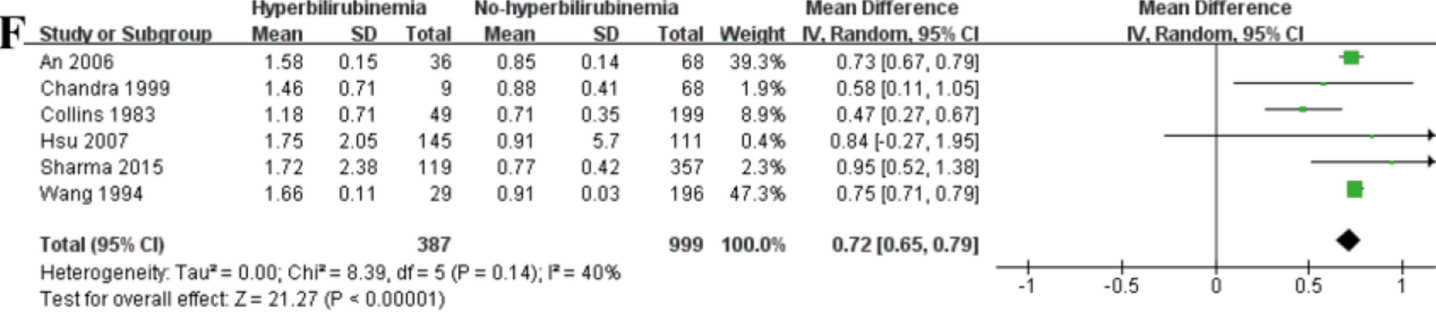

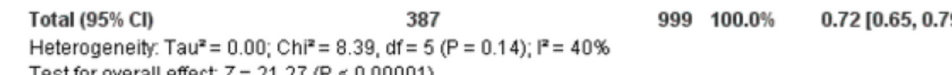

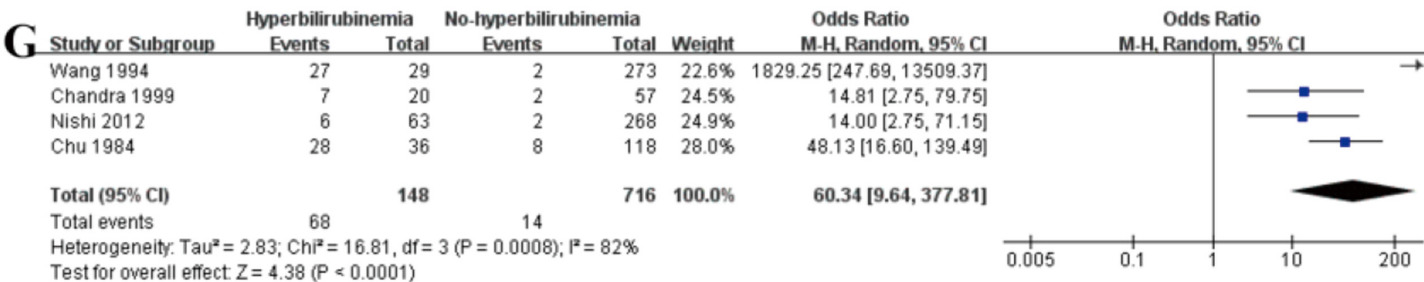

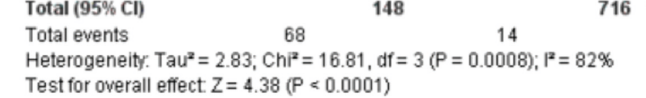

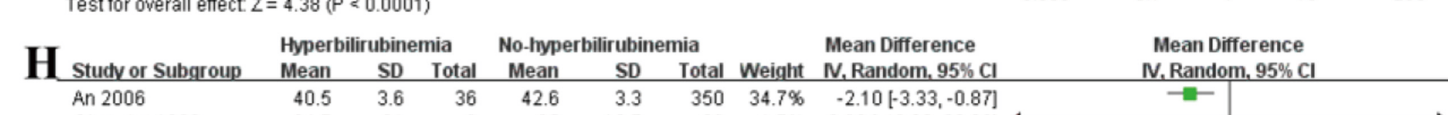

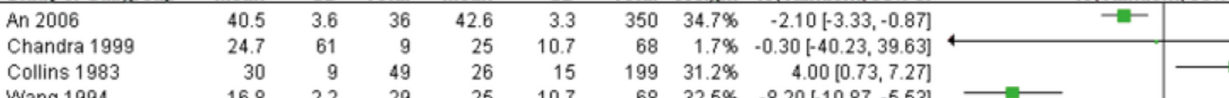

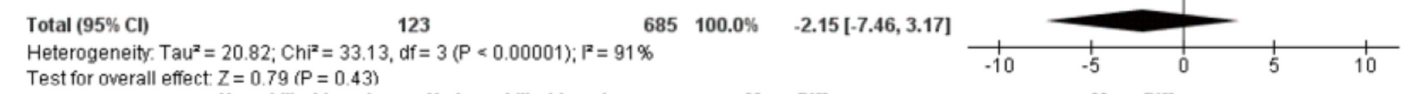

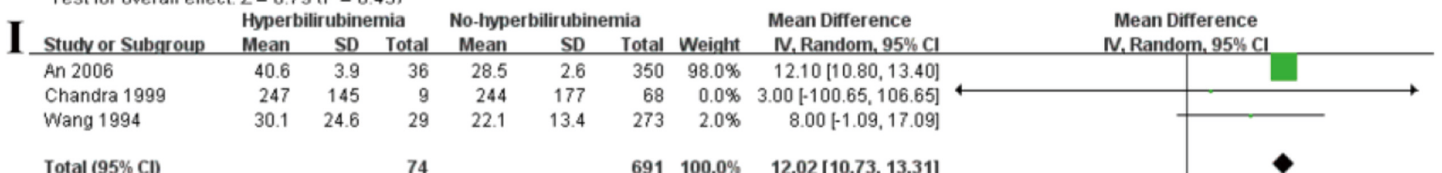

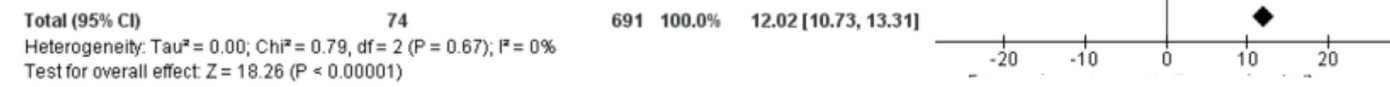

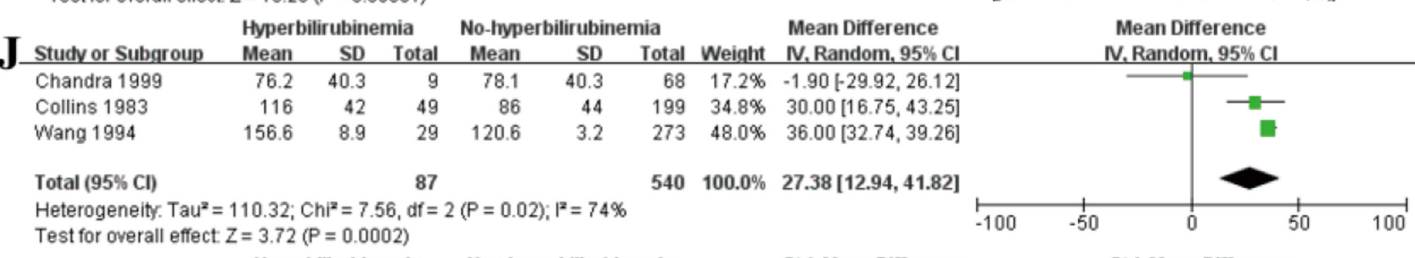

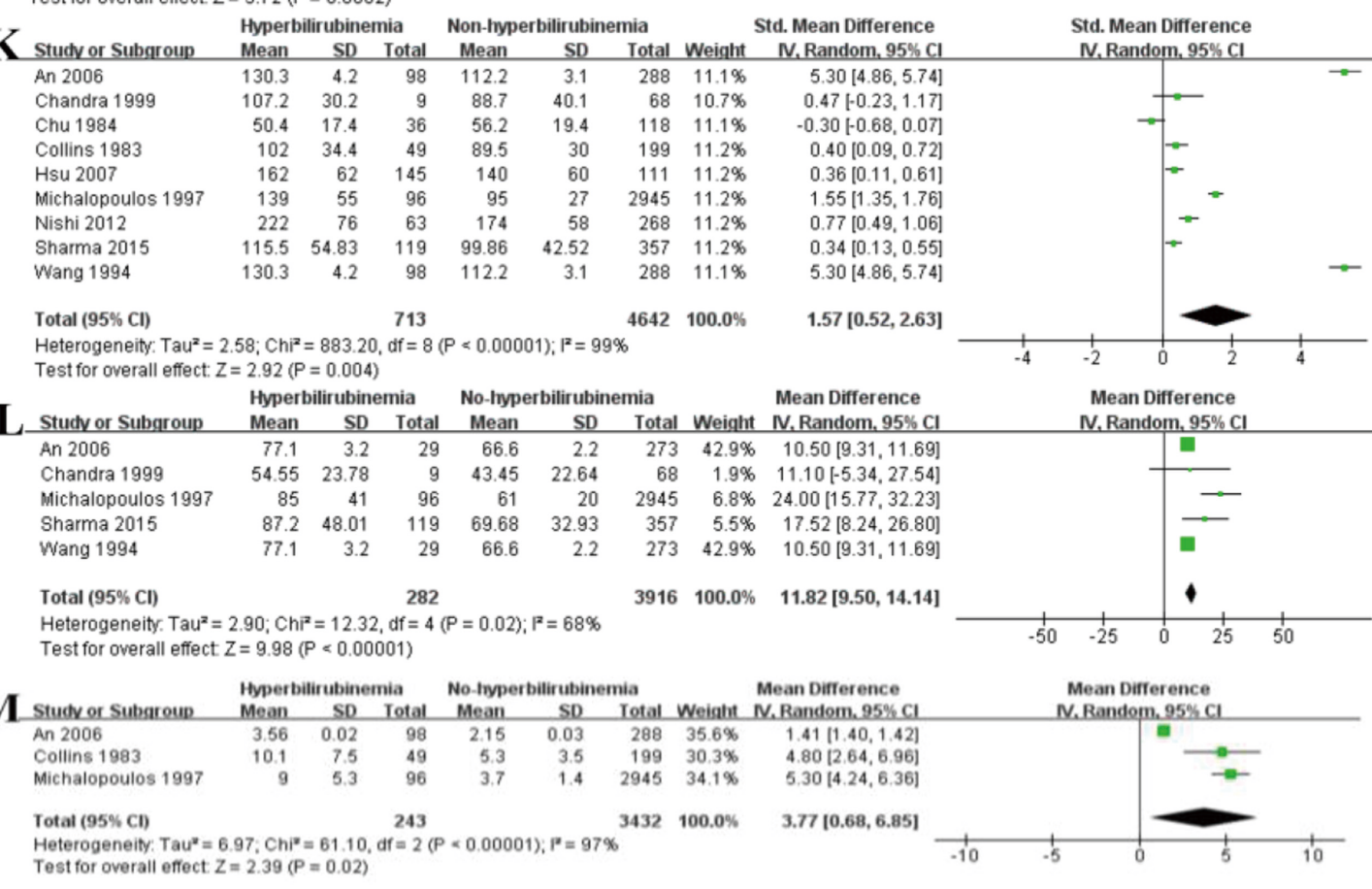

Figure S1 Forest plots of preoperative and intraoperative risk factors for postoperative hyperbilirubinemia after cardiac surgery. The included risk factors were (A) age, (B) sex, (C) body surface area, (D) right atrial pressure, (E) minimum esophageal temperature, (F) preoperative bilirubin concentration, (G) preoperative elevated bilirubin concentration, (H) aspartate amino transferase, (I) alanine aminotransferase, (I) alkaline phosphatase, (K) CPB time, (L) ACC time, and (M) the amount of blood transfused. $\mathrm{CPB}$, cardiopulmonary bypass; $\mathrm{ACC}$, aortic cross-clamp; CI, confidence interval. 
Table S3 Sensitivity analyses of pooled mortality associated with hyperbilirubinemia

\begin{tabular}{lccc}
\hline Excluding studies & No. of studies & Incidence rate $(95 \% \mathrm{Cl})$ & Heterogeneity $\left(\mathrm{I}^{2}\right)$ \\
\hline$<100$ participants & 8 & $10.99(5.62-21.49)$ & $66 \%$ \\
Non-emergency surgery & 8 & $12.30(6.61-21.87)$ & $46 \%$ \\
$<100$ participants and non-emergency surgery & 7 & $13.05(7.52-22.66)$ & $34 \%$ \\
Isolated heart valve surgery & 8 & $9.01(4.35-18.68)$ & $67 \%$ \\
Isolated heart transplantation & 8 & $11.02(5.00-24.28)$ & $69 \%$ \\
\hline
\end{tabular}

Cliconidencenterat

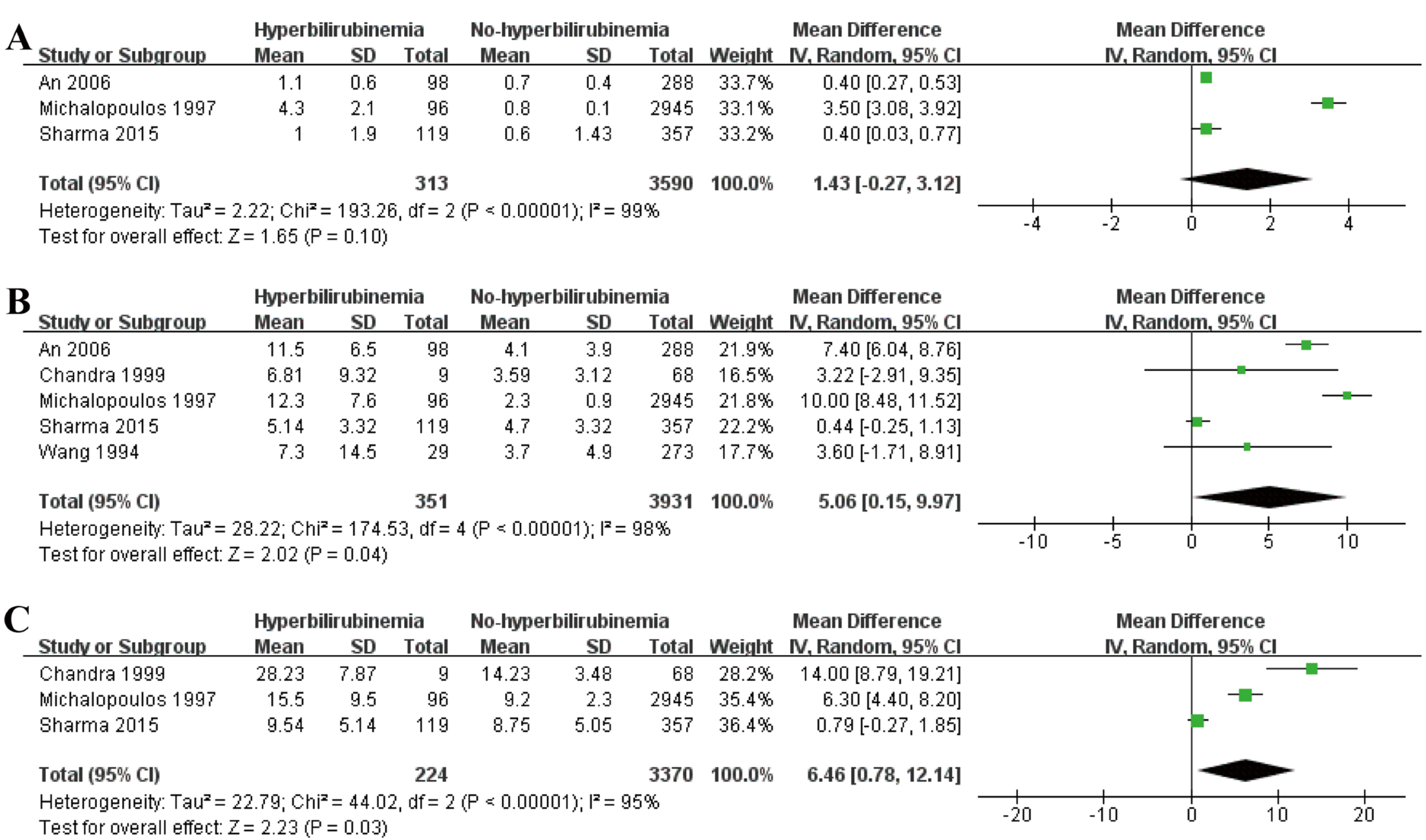

Figure S2 Forest plots of the associations of duration of mechanical ventilation (A), ICU stay (B), and hospital stay (C) with postoperative hyperbilirubinemia. CI, confidence interval.

\section{Funnel Plot of Standard Error by Log odds ratio}

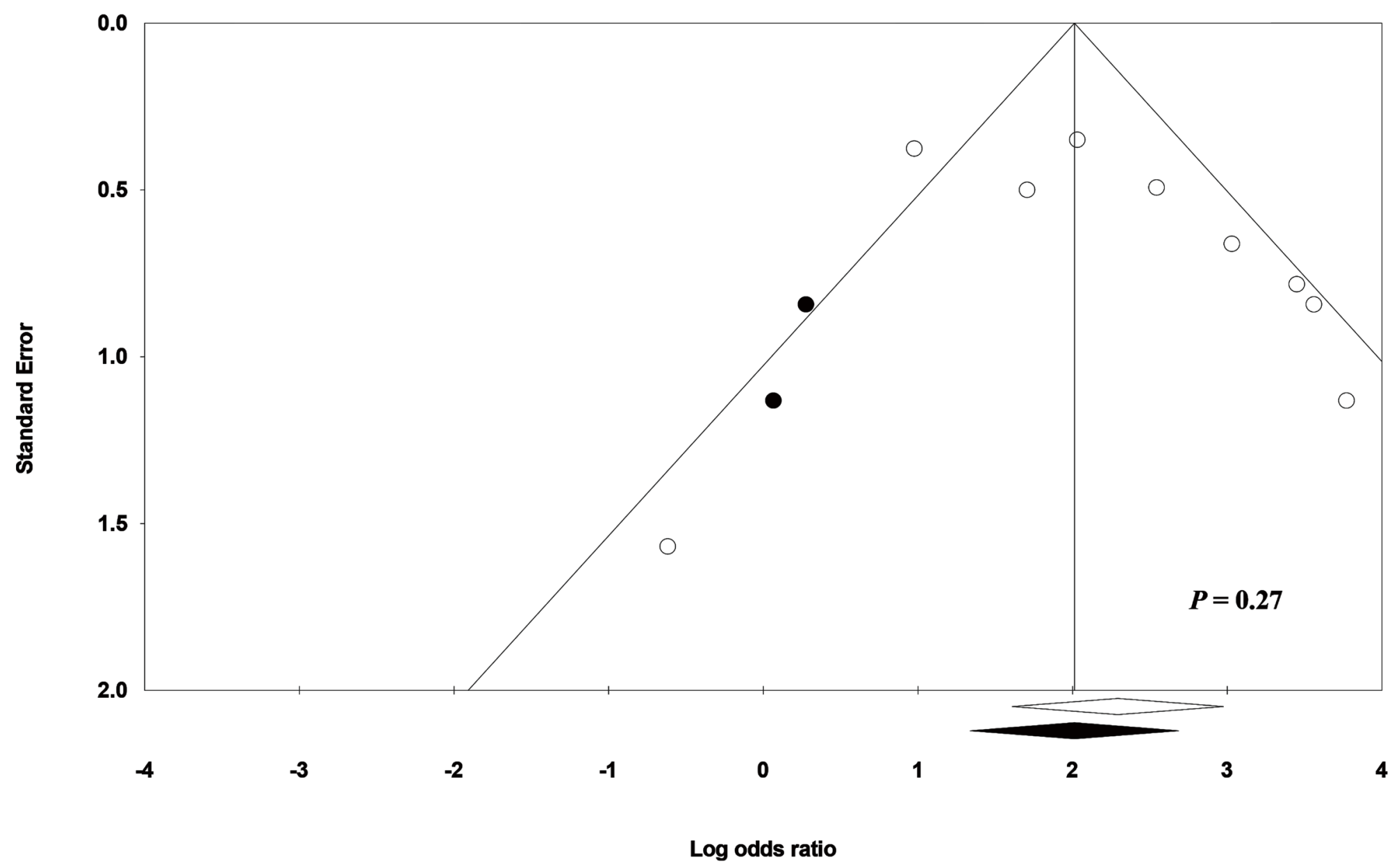

Figure S3 Funnel plots of studies to evaluate publication bias in in-hospital mortality risks. 